\title{
Influence of hydrodynamic setting on Posidonia oceanica meadow landscape and architecture
}

\author{
Pace Matthew ${ }^{1 *}$, Borg Joseph A. ${ }^{1}$, Galdies Charles ${ }^{2}$ \\ ${ }_{1}$ Department of Biology, University of Malta, Msida, Malta \\ ${ }^{2}$ Environmental Management and Planning Division, Institute of Earth Systems, \\ University of Malta, Msida, Malta \\ *matthew.e.pace@gmail.com
}

Seagrass meadow characteristics, including distribution, shape, size, and withinmeadow architectural features may be influenced by various physical factors, including hydrodynamic forces. However, such influence has hardly been assessed for meadows of the ecologically important and endemic Mediterranean seagrass Posidonia oceanica. Estimates of wind-generated wave energy and the energy attenuated by depth were computed by a hydrodynamic model, WEMo (Wave Exposure Model), for five sites on the north-eastern coast of the Maltese Islands which each supported patchy, reticulate and continuous bed types of Posidonia oceanica. The distribution of $P$. oceanica meadows at these sites were mapped to a depth of circa $15 \mathrm{~m}$ using a combination of aerial photography and SCUBA diving surveys. Data on meadow architectural attributes were collected for each of the three $P$. oceanica bed types at each of the five study sites. Metrics for $P$. oceanica landscape features were calculated via FRAGSTATS v4 for replicate $2500 \mathrm{~m}^{2}$ subsamples that were extracted from the seagrass habitat maps. The results indicate that landscape and architectural features of relatively deep $P$. oceanica meadows are significantly influenced by the hydrodynamic setting. $P$. oceanica meadows tend to be patchier with lower overall cover, more complex patch shapes and reduced architectural complexity along a wave exposure gradient from low to high energy. The findings from the present study highlight the importance of understanding the influence of hydrodynamic factors on the natural dynamism of seagrass meadow landscape and architecture for the conservation and management of $P$. oceanica habitat. 